\title{
A prospective study on evaluation of maternal and foetal outcomes of hypothyroidism with levothyroxine and prevalence of hypothyroidism in pregnancy in a tertiary care teaching hospital in Kerala
}

\author{
Shajil A. Justin ${ }^{1}$, Merin S. Johnson²* \\ ${ }^{1}$ Department of Pharmacology, Dr. Somervell Memorial C.S.I Medical College and Hospital, Karakonam, Kerala, \\ India \\ ${ }^{2}$ Department of Obstetrics and Gynaecology, Government Hospital, Kuzhithurai, Tamil Nadu, India \\ Received: 02 February 2020 \\ Revised: 17 February 2020 \\ Accepted: 18 February 2020 \\ *Correspondence: \\ Dr. Merin S. Johnson, \\ Email: shajilsheena@gmail.com \\ Copyright: (c) the author(s), publisher and licensee Medip Academy. This is an open-access article distributed under \\ the terms of the Creative Commons Attribution Non-Commercial License, which permits unrestricted non-commercial \\ use, distribution, and reproduction in any medium, provided the original work is properly cited.
}

\begin{abstract}
Background: Pregnancy influences a profound alteration in thyroid function and hypothyroidism has a massive impact on adverse pregnancy outcomes. An appropriate treatment with appropriate dose of levothyroxine is much essential during pregnancy. The present study evaluates the effect of levothyroxine dose in preventing maternal and foetal outcomes and the prevalence of hypothyroidism among pregnant women.

Methods: 1500 antenatal women with singleton gestation attending outpatient of Obstetrics and Gynaecology Department, were analysed. Apart from routine obstetrical investigations, thyroid stimulating hormone (TSH) tests were done at the first antenatal visit. Patients were followed up till delivery after levothyroxine treatment. Their obstetrical and perinatal outcomes were noted. TSH estimation was done 3 days after delivery in new-borns to screen for neonatal thyroid disorders.

Results: The prevalence of hypothyroidism was $10.54 \%$. The common adverse maternal and foetal complications were preeclampsia $(15.19 \%)$ and low birth weight babies $(17.72 \%)$ respectively. The mean age of pregnant women was 26.66 years. As age advances there is an increased risk of developing hypothyroidism in pregnancy. Levothyroxine $25 \mu \mathrm{g}$ daily was highly prescribed in $63.92 \%$ hypothyroid patients.

Conclusions: Overall, the prevalence of hypothyroidism was high. Since maternal and foetal complications were higher in patients with hypothyroidism, levothyroxine treatment had decreased the risk of maternal and foetal outcome. Pre-pregnancy screening should be implemented at least in patients with high risk factors for thyroid dysfunction. Universal screening for new-borns is also recommended to detect hypothyroidism. Expert decisions and cost-effectiveness studies will promulgate the impact of universal screening.
\end{abstract}

Keywords: Hypothyroidism, Prevalence, Levothyroxine

\section{INTRODUCTION}

Thyroid disorders are the commonest endocrine disorders affecting women of reproductive age group. ${ }^{1}$ Hypothyroidism is the second most common endocrinopathies found in pregnancy, first being diabetes. $^{2}$ Pregnancy is a stressful condition to the maternal thyroid gland and is associated with intense changes in the regulation of thyroid function. There is $30 \%$ to $100 \%$ increase in total triiodothyronine and thyroxine concentrations, two to threefold increase in thyroxine-binding globulin concentration, increased 
serum thyroglobulin, and increased renal iodide clearance. ${ }^{3}$ Furthermore, human chorionic gonadotropin hormone (beta-HCG), during pregnancy has mild thyroid stimulating activity as it has structural similarities with thyroid stimulating hormone (TSH). ${ }^{4}$

Thyroid hormone is critical for normal foetal brain development, neuronal multiplication, migration and structural organization, thus on future intellectual development. During early pregnancy, the foetus is totally dependent on maternal thyroid hormone supply. Foetal thyroid gland starts producing hormones from 810 weeks of gestation and significant amounts after midgestation. $^{5}$ Maternal thyroid hormone excess or deficiency can influence the outcome of mother and foetus at all stages of pregnancy. The most frequent thyroid disorder in pregnancy is maternal hypothyroidism.

According to the western literature the prevalence of hypothyroidism in pregnancy is around $2.5 \% .^{6}$ According to few Indian studies the prevalence of hypothyroidism in pregnancy is ranging from $4.8 \%$ to $14.3 \% .^{7-10}$

In pregnancy, physiological changes like fatigue, sluggishness, constipation, oedema may simulate hypothyroidism. Thyroid dysfunction in pregnancy may lead to abortion, placental abruption, pre-eclampsia, preterm delivery, low birth weight babies, foetal growth restriction, neonatal hyperbilirubinemia and reduced intellectual function in the offspring. ${ }^{5}$

It is best to screen women early in the pregnancy for thyroid dysfunction. They are common, treatable, and to some extent preventable conditions which produce morbidity and pose special risks for pregnancy and the developing foetus. Screening for thyroid dysfunction in a woman who is pregnant is important because thyroid hormone status is directly related to foetal brain development. Reference ranges of TSH obtained from non-pregnant populations do not reflect normal values in pregnant women because of their physiologic changes in thyroid function. ${ }^{11}$ As per the American thyroid society and Indian thyroid society recommendations, the following reference ranges are recommended during pregnancy. 1st trimester was 0.1 to $2.5 \mathrm{mIU} / 1$, 2nd trimester was 0.2 to $3.0 \mathrm{mIU} / \mathrm{l}, 3 \mathrm{rd}$ trimester was 0.3 to $3.0 \mathrm{mIU} / \mathrm{l}^{12,13}$ Notably, the lower reference limit of TSH concentrations is also decreased in pregnant women, so euthyroid women can be diagnosed as hyperthyroid if non-pregnant reference ranges are used. ${ }^{14}$

The objective of this study was to evaluate the benefit of levothyroxine at different doses in preventing maternal and foetal outcomes and to analyse the prevalence of hypothyroidism among the pregnant women with an ultimate aim of creating awareness on pre-conceptional screening for all antenatal women.

\section{Ethical approval}

This study was approved by the Institutional Ethics Committee of PVS Hospital (P) Ltd, [PVS/EC/02/13-14], (dated 12th October 2013).

\section{METHODS}

This is a prospective analytical study which was carried out in a total of 1500 antenatal women attending OPD of first and second units in the Department of Obstetrics and Gynaecology, PVS Hospital, Calicut, which is a 310 bedded multi-specialty hospital with a full-fledged obstetrics and gynaecology department with up to 1700 deliveries per year. Of the 1500 pregnant women, 1407 women had their first visit during first trimester and 93 women had their first visit during second trimester. The duration of study was for two year i.e., from October 2013 to October 2015.

All women with singleton gestation attending OBG outpatient department, PVS hospital, Calicut, were included irrespective of their gravida status and the period of gestation. Women with documented history of hypothyroidism and on treatment, multiple pregnancies, gestational trophoblastic diseases, pregestational diabetes and past history of thyroid disorders were excluded from analysis.

After obtaining informed consent from the patient, detailed history was taken in a prescribed proforma. Physical examination was done to look for thyroid enlargement and to ascertain the pregnancy. Apart from recommended routine antenatal investigations, TSH estimation during their first visit was also done. The reference ranges of the test values used in this study were as per the guidelines of American Thyroid Association for the diagnosis and management of thyroid disease during pregnancy and postpartum. ${ }^{12}$ As per ATA Guidelines, if trimester-specific ranges for TSH are not available in the laboratory, the following upper normal reference ranges are recommended: 1 st trimester ws 0.1 to $2.5 \mathrm{mIU} / 1$, 2nd trimester was 0.2 to $3.0 \mathrm{mIU} / 1$, $3 \mathrm{rd}$ trimester was 0.3 to $3.0 \mathrm{mIU} / \mathrm{l}$.

Women with hypothyroidism were treated with levothyroxine and monitored by repeat tests every trimester and the doses of the levothyroxine were adjusted to keep serum TSH within normal limit $\leq 2.5$ $\mathrm{mIU} / \mathrm{l}$ in first trimester and $\leq 3.0 \mathrm{mIU} / \mathrm{l}$ in second and third trimester. All pregnant women were followed throughout the pregnancy and allowed to continue till 40 weeks of gestation, unless termination was indicated for maternal or foetal indications. Adverse pregnancy outcomes like preeclampsia, abruption, preterm delivery, abortions, intrauterine growth restriction (IUGR), foetal distress, low birth weight were analysed. TSH estimation was done 3 days after delivery in new-borns to screen for neonatal thyroid disorders. The reference range used for neonatal TSH was $<40 \mathrm{uIU} / \mathrm{ml}$ at 72 hours of life. 
The collected data was analysed statistically using SPSS version 16 software package. Data was analysed by Pearson's chi square test. A p value of less than 0.05 was considered to indicate statistical significance.

\section{RESULTS}

In this study, a total of 1500 antenatal women attending outpatient Department of Obstetrics and Gynaecology were included. Of the total population analysed, 158 $(10.54 \%)$ were found to have hypothyroidism in pregnancy and $1342(89.46 \%)$ women were euthyroid (Table 1).
Table 1: Distribution of the population according to thyroid status.

\begin{tabular}{|lll|}
\hline & Number & Percentage (\%) \\
\hline Euthyroid & 1342 & 89.46 \\
\hline Hypothyroid & 158 & 10.54 \\
\hline
\end{tabular}

With regard to the age wise distribution of screened population for euthyroid and antenatal women with hypothyroidism. As the age advances there is an increased risk of developing hypothyroidism in pregnancy. This observation is statistically significant $(\mathrm{p}=0.019)$ (Table 2).

Table 2: Age wise distribution of screened population.

\begin{tabular}{|c|c|c|c|c|c|}
\hline \multirow{2}{*}{ Age (in years) } & \multicolumn{2}{|c|}{ Euthyroid (n=1342) } & \multicolumn{2}{|c|}{ Hypothyroid (n=158) } & \multirow{2}{*}{$\mathbf{P}$ value } \\
\hline & Number & $\%$ & Number & $\%$ & \\
\hline$\leq \mathbf{2 0}$ & 91 & 83.49 & 18 & 16.51 & \multirow{5}{*}{0.019} \\
\hline 21-25 & 520 & 92.53 & 42 & 7.47 & \\
\hline 26-30 & 491 & 89.11 & 60 & 10.89 & \\
\hline 31-35 & 184 & 89.76 & 21 & 10.24 & \\
\hline$\geq 36$ & 56 & 76.71 & 17 & 23.29 & \\
\hline
\end{tabular}

Table 3: Association of hypothyroid and maternal complication.

\begin{tabular}{|lll|lll|}
\hline Antenatal & \multicolumn{2}{l}{ Euthyroid $(\mathbf{n = 1 3 4 2})$} & Hypothyroid $(\mathbf{n = 1 5 8 )}$ & P \\
complications & Number & \% & Number & \% & \\
\hline No complication & 1012 & 75.41 & 104 & 15.19 & 0.01 \\
\hline Preeclampsia & 125 & 9.31 & 24 & 12.02 & 0.453 \\
\hline Preterm labour & 143 & 10.65 & 19 & 6.33 & 0.13 \\
\hline Abortion & 47 & 3.5 & 10 & 0.63 & 0.5 \\
\hline Abruption & 15 & 1.12 & 1 & & \\
\hline
\end{tabular}

Table 4: Association of hypothyroid and foetal complications.

\begin{tabular}{|lll|lll|}
\hline Foetal & \multicolumn{2}{l}{ Euthyroid $(\mathbf{n = 1 3 4 2})$} & Hypothyroid $(\mathbf{n = 1 5 8 )}$ & P value \\
Complications & Number & \% & Number & \% & \\
\hline No complications & 742 & 55.32 & 67 & 42.41 & 0.7 \\
\hline LBW & 227 & 16.91 & 28 & 17.72 & 0.02 \\
\hline Foetal distress & 100 & 7.45 & 23 & 12.02 & 0.453 \\
\hline Preterm birth & 143 & 10.66 & 19 & 6.33 & 0.264 \\
\hline IUGR & 80 & 5.96 & 10 & 6.33 & 0.13 \\
\hline Abortion & 47 & 3.51 & 10 & 0.63 & 0.3 \\
\hline IUD & 3 & 0.22 & 1 & & \\
\hline
\end{tabular}

Among the association of hypothyroid with the maternal complication, $15.19 \%$ of hypothyroid patients had preeclampsia while it is only $9.31 \%$ in euthyroid patients. This observation was found to be statistically significant $(\mathrm{p}=0.01) .12 .02 \%$ of hypothyroid patients and $10.65 \%$ of euthyroid population were found to have preterm delivery. The incidence of preterm delivery was more in hypothyroid population but had not shown a statistically significant difference between them. Abortion was noted in $6.33 \%$ of patients with hypothyroidism, while it was $3.5 \%$ in euthyroid patients. The incidence of abortion was more in hypothyroid patients but had not shown a statistically significant difference between them.
Abruption was noted in $0.63 \%$ of hypothyroid patients while it was $1.12 \%$ in euthyroid patients and this observation was found to be statistically not significant $(\mathrm{p}=0.5)($ Table 3).

With respect to the association of hypothyroid and foetal complications, the lower birth weight babies are higher with $17.72 \%$ of patients when compared to other foetal complications in hypothyroidism and its $16.91 \%$ in euthyroid women. The result is statistically insignificant. The foetal distress was noted in $14.56 \%$ of patients with hypothyroidism whereas it was $7.45 \%$ in euthyroid population. This observation was found to be statistically 
significant $(\mathrm{p}=0.02)$. Here, preterm birth was noted in $12.02 \%$ followed by Foetal distress in hypothyroid patients, whereas its $10.66 \%$ in euthyroid pregnant mother. Among hypothyroid patients $6.33 \%$ had IUGR while it was $5.96 \%$ in euthyroid population. This observation was not found to be statistically significant. Also, $17.72 \%$ of hypothyroid patients and $16.91 \%$ of euthyroid population were found to have delivered babies of weight $\leq 2.5 \mathrm{~kg}$. IUD was noted in $0.63 \%$ of hypothyroid patients and $0.22 \%$ of euthyroid patients. Abortion was noted in $6.33 \%$ of patients with hypothyroidism while it was $3.5 \%$ in euthyroid patients (Table 4).

Table 5: Distribution of hypothyroid population according to treatment.

\begin{tabular}{|lll|}
\hline Treatment & Number & Percentage $(\%)$ \\
\hline L-thyroxine $\mathbf{2 5} \boldsymbol{\mu g}$ & 101 & 63.92 \\
\hline L-thyroxine $\mathbf{5 0} \boldsymbol{\mu g}$ & 44 & 27.85 \\
\hline L-thyroxine $\mathbf{7 5} \boldsymbol{\mu g}$ & 7 & 4.43 \\
\hline L-thyroxine $\mathbf{1 0 0} \boldsymbol{\mu g}$ & 6 & 3.80 \\
\hline
\end{tabular}

Table 5 shows the distribution of hypothyroid population on treatment, of which $63.92 \%$ of hypothyroid patients required L-thyroxine $25 \mu \mathrm{g}$ on daily basis, whereas $27.85 \%$ required levothyroxine $50 \mu \mathrm{g}$ daily, a less percentage of $4.43 \%$ required levothyroxine $75 \mu \mathrm{g}$ daily and a higher dose of levothyroxine $100 \mu \mathrm{g}$ daily was needed for $3.80 \%$ of antenatal population.

\section{DISCUSSION}

This clinical study was conducted to assess the maternal and fetal outcomes with levothyroxine and to analyze the prevalence of hypothyroidism in pregnancy outpatients of Obstetrics and Gynaecology Department. Out of 1500 antenatal women, $158(10.54 \%)$ were found to have hypothyroidism and $1342(89.46 \%)$ were euthyroid. All the patients with hypothyroidism were treated with levothyroxine and followed up in euthyroid state till delivery. Also, the fetal and maternal outcomes were compared to that of the euthyroid group.

\section{Association of hypothyroidism in pregnancy with age and parity}

The mean age of pregnant women in this study was 26.66 years $(\mathrm{SD}=4.00)$, which was lower compared to western studies by Vaidya et al. ${ }^{15}$ This reflects early marriage and early conception prevalent in our area. In this study, the occurrence of thyroid dysfunction in pregnancy has showed an increasing trend as the maternal age advances (10.24\% vs $23.29 \%, \mathrm{p}=0.019)$. A study by Ajmani et al, has also shown an increased occurrence of thyroid dysfunction with advancing maternal age. ${ }^{7}$ Increased incidence of hypothyroidism was noted in multigravida; however, it is statistically not significant. This was comparable with the study by Ajmani et al. ${ }^{7}$

\section{Association of hypothyroidism in pregnancy and preeclampsia}

The incidence of preeclampsia was $15.19 \%$ in patients having hypothyroidism and $9.31 \%$ in euthyroid patients. This finding is statistically significant $15.19 \%$ vs $9.31 \%$, $(\mathrm{p}=0.01)$. The incidence of preeclampsia in hypothyroidism in the present study is compared with other studies below.

Ajmani et al reported incidence of preeclampsia (38.9\%) in hypothyroidism and $(7.8 \%)$ in euthyroid status, where the hypothyroidism incidence is less in our study but the euthyroid incidence is almost similar to the previous study. ${ }^{7}$ Similarly, in western studies by Leung et al and Davis et al the findings were comparable to our study. ${ }^{16,17}$

\section{Association of hypothyroidism in pregnancy and preterm labor}

In this study $12.02 \%$ of patients with hypothyroidism had preterm delivery while it was $10.65 \%$ in euthyroid. The incidence of preterm labor is compared with various studies below. In a study by Ajmani et al, the incidence of preterm labor was $39.1 \%$ and $25 \%$ in hypothyroidism and euthyroid respectively which was high and not consistent with our study. ${ }^{7}$ In our study, the low incidence can be attributed to the early detection and better control of thyroid dysfunction in the study group. Stagnaro, reported that women with high TSH levels has threefold increase in risk of preterm delivery. ${ }^{18}$

\section{Association of hypothyroidism in pregnancy and abortion}

In this study, $6.33 \%$ abortions were noted in hypothyroidism patients and $3.51 \%$ in euthyroid patients. In a study by Ajmani et al, incidence of abortion was $8.3 \%$ in pregnant women with hypothyroidism which was higher when compared to our study. ${ }^{7}$ Abalovich et al, reported that untreated hypothyroidism at the time of conception is associated with miscarriage rate of $31.4 \%$ compared with $4 \%$ in euthyroid subjects. ${ }^{19}$ Similar to our study out of 10 abortions, $4(40 \%)$ miscarriages in hypothyroidism were untreated as these patients had their first visit and TSH measurement was done after 9 weeks of gestation which is also, in parallel to a study by negro et al. ${ }^{20}$

In a study by Goldman et al, miscarriage rates were almost the same in hypothyroid patients and euthyroid group, where the cut off for hypothyroidism was TSH $>4.29 \mathrm{mU} / \mathrm{l}^{21}$ Lower incidence of abortion in our study could probably be the result of early detection and good control of thyroid dysfunction with medications.

\section{Association of hypothyroidism in pregnancy and abruption}

In this study, incidence of abruption was $0.63 \%$ in hypothyroidism patients and $1.12 \%$ in euthyroid patients. 
This association was found to be statistically not significant $(0.63 \%$ vs $1.12 \%) \quad(\mathrm{p}=0.5)$. Ajmani et al reported an incidence of $16.6 \%$ in hypothyroidism which is higher than our study. ${ }^{7}$ Our study had $1(0.63 \%)$ case of abruption in hypothyroid patients $(10 \%)$, which is very less compared to studies by Abalovich et al and Davis et al. ${ }^{17,19}$

\section{Association of hypothyroidism in pregnancy and low birth weight}

The incidence of low birth weight (birth weight $<2.5 \mathrm{~kg}$ ) was $17.72 \%$ in patients having hypothyroidism and $16.91 \%$ in euthyroid group. The incidence of low birth weight babies in hypothyroidism in the present study is compared with other studies below. When compared to our study, the low birth weight babies in hypothyroidism were very high in studies conducted by Leung et al, Ajmani et al and Davis et al. ${ }^{7,16,17}$

\section{Association of hypothyroidism in pregnancy and fetal distress}

Fetal distress in our study was noted in $14.56 \%$ of patients having hypothyroidism whereas it was $7.45 \%$ in euthyroid population. There was an increased incidence of fetal distress in population having thyroid dysfunction. This observation was found to be statistically significant (14.56\% vs $7.45 \%, p=0.02)$. This was lower when compared to a study by Goel et al who reported a higher incidence of fetal distress $(20 \%)$ in pregnancies complicated by maternal hypothyroidism. ${ }^{22}$ Fetal distress in labor could be due to increased incidence of hypothyroidism exerting irreversible effects on the fetus and placenta in early pregnancy. These irreversible effects impaired their subsequent ability to tolerate stress, thereby increasing the incidence of fetal distress in labor.

\section{Association of hypothyroidism in pregnancy and IUGR}

In this study $6.33 \%$ of patients with thyroid dysfunction had IUGR while it was $5.96 \%$ in euthyroid patients. This finding is comparable to a study by Sahu et al where the incidence of IUGR in hypothyroidism was $8.1 \%$ which stands very similar to our present study. ${ }^{8}$

\section{Association of hypothyroidism in pregnancy and levothyroxine treatment}

Levothyroxine (T4) is the major hormone produced by the thyroid gland. In our study, starting with low dose of levothyroxine $25 \mu \mathrm{g}$ on daily basis was required for $63.92 \%$ of antenatal women which was sufficient to maintain an euthyroid state in pregnant hypothyroid women and also higher dose of levothyroxine $100 \mu \mathrm{g}$ daily was required very less $(3.80 \%)$, which remains inconsistent with Kashi et al where $84 \%$ of the pregnant hypothyroid women studied, needed an increase in their levothyroxine dose. ${ }^{23}$ These results also agree with other studies that suggested the levothyroxine dose should be increased during pregnancy. ${ }^{24-28}$ But in our present study, escalated dose of levothyroxine was not required. There are few explanations possible for this increased requirement for levothyroxine during pregnancy like the increased level of TBG, increase in plasma volume and the influence of the mass of the foetal-placental unit are the reasons. ${ }^{24,29}$ Thyroxine metabolism by the foetal placental unit can be a possible cause of an incremented requirement for levothyroxine in the later phases of gestation and a reduce in the need after parturition. ${ }^{30}$ To maintain adequate concentrations of thyroid hormone during pregnancy, T4 and triiodothyronine (T3) production are increased physiologically by the thyroid gland throughout a normal pregnancy which is unseen in hypothyroid women.

\section{Prevalence of hypothyroidism}

The prevalence of hypothyroidism constituted $10.54 \%$ in our study. Sahu et al has reported prevalence of hypothyroidism to be $11.05 \%$, which is in line with our prevalence study. ${ }^{8}$ Dhanwal et al from Delhi, reported a prevalence of hypothyroidism as $14.3 \%$, with a cut off of $4.5 \mathrm{mIU} / \mathrm{l}$ as upper limit of normal. ${ }^{9}$ In another study from Delhi, Ajmani et al reported a prevalence of $13.25 \%$ amongst 400 pregnant women in 2 nd trimester at a cut off of $3.0 \mathrm{mIU} / \mathrm{l}^{7}$

The maternal and foetal complications were considerably less in patients with thyroid dysfunction after detection and treatment with levothyroxine, but still there is not much significant improvement in maternal and foetal outcome grossly. Hence pre-conceptional counselling and correction of thyroid dysfunction at the earliest when pregnancy is confirmed is essential. Pregnancy in euthyroid state will have the optimum results.

\section{CONCLUSION}

The prevalence of hypothyroidism was high in this study. The maternal and fetal complications were higher in patients with hypothyroidism. Hence all pregnant women should have screening for thyroid function status as early as the pregnancy is confirmed. This is to prevent central nervous system developmental delay in the new-borns, as the foetus depends on maternal thyroxine till 10 weeks of pregnancy. Foetal and maternal outcome will be optimum if the person conceives at the euthyroid state. Patients diagnosed with hypothyroidism should be treated with levothyroxine. Increases in levothyroxine dosage administered in pregnancy appear to be indispensable in the majority of patients with well-controlled hypothyroidism, especially in the first trimester. However, this change was not universal and levothyroxine dosage decreased in a few cases and remained unchanged in others too. We suggest individualization of LT4 therapy for every pregnant woman. Levothyroxine use was associated with a decreased risk of pregnancy loss in this study. Hence it is ideal to have pre-conceptional screening to detect and 
manage thyroid dysfunction before conception. Prepregnancy screening should be implemented at least in patients with high risk factors for thyroid dysfunction. Hypothyroidism in pregnancy should be diagnosed with reference to the lower levels of TSH values in each trimester compared to the non-pregnant levels. Universal screening for new-borns is also recommended to detect hypothyroidism.

\section{ACKNOWLEDGEMENTS}

Our heartfelt thanks to all the staff of Department of Obstetrics and Gynecology, PVS Hospital, Calicut, Kerala, for their constant support throughout the study without which this study would not be possible.

Funding: No funding sources

Conflict of interest: None declared

Ethical approval: The study was approved by the Institutional Ethics Committee of PVS Hospital (P) Ltd

\section{REFERENCES}

1. Akhtar MA, Agrawal R, Brown J, Sajjad Y, Craciunas L. Thyroxine replacement for subfertile women with euthyroid autoimmune thyroid disease or subclinical hypothyroidism. Cochrane Database Systematic Rev. 2019;25:6:CD011009.

2. Amudha P, Karthika Devi A, Manochithra B, Delphin Supriya J. Implications of combined endocrinopathy of diabetes mellitus and hypothyroidism on pregnancy. Int $\mathbf{J}$ Reprod Contracept Obstetr Gynaecol. 2017;6(1):266-70.

3. Smallridge RC, Glinoer D, Hollowell JG, Brent G. Thyroid function inside and outside of pregnancy: what do we know and what don't we know? Thyroid. 2005;15:54-9.

4. Casey B, Leveno K. Thyroid disease in pregnancy. Obstetr Gynecol. 2006;108(5):1283-92.

5. Girling J. Thyroid disease in pregnancy. Obstetr Gynaecol Reprod Med. 2008;18:10.

6. LeBeau SO, Mandel SJ. Thyroid disorders during pregnancy. Endocrinol Metabol Clin North Am. 2006;35:117-36.

7. Nangia AS, Aggarwal D, Bhatia P, Sharma M, Sarabhai V, Paul M. Prevalence of Overt and Subclinical Thyroid Dysfunction among Pregnant Women and Its Effect on Maternal and Fetal Outcome. J Obstetr Gynaecol India. 2014;64(2):10510.

8. Sahu MT, Das V, Mittal S, Agarwal A, Sahu M. Overt and subclinical thyroid dysfunction among Indian pregnant women and its effect on maternal and fetal outcome. Arch Gynecol Obstetr. 2010;281(2):215-20.

9. Dhanwal DK, Bajaj S, Rajput R, Subramaniam KA, Chowdhury S, Bhandari R, et al. Prevalence of hypothyroidism in pregnancy: An epidemiological study from 11 cities in 9 states of India. Indian J Endocrinol Metabol. 2016;20:387-90.
10. Nambiar V, Jagtap VS, Sarathi V, Lila AR, Kamalanathan S, Bandgar TR, et al. Prevalence and Impact of Thyroid Disorders on Maternal Outcome in Asian-Indian Pregnant Women. J Thyroid Res. 2011;2011:429097.

11. De Groot L, Abalovich M, Alexander EK, Amino N, Barbour L, Cobin RH, et al. Management of thyroid dysfunction during pregnancy and postpartum: an Endocrine Society clinical practice guideline. J Clin Endocrinol Metabol. 2012;97(8):2543-65.

12. Stagnaro-Green A, Abalovich M, Alexander E, Azizi F, Mestman J, Negro R, et al. Guidelines of the American Thyroid Association for the diagnosis and management of thyroid disease during pregnancy and postpartum. Thyroid. 2011;21(10):1081-25.

13. Dave A, Maru L, Tripathi M. mportance of Universal screening for thyroid disorders in first trimester of pregnancy. Indian J Endocrinol Metabol. 2014;18(5):735-8.

14. Männistö T. Thyroid Disease During Pregnancy: options for management. Expert Rev Endocrinol Metabol. 2013;8(6):537-47.

15. Vaidya B, Anthony S, Bilous M, Shields B, Drury J, Hutchison S, et al. Detection of thyroid dysfunction in early pregnancy: Universal screening or targeted high-risk case finding? J Clin Endocrinol Metabol. 2007;92(1):203-7.

16. Leung AS, Lynne KM, Koonings PP, Montoro M, Mestman JH. Perinatal outcome in hypothyroid pregnancies. Obstetr Gynecol. 1993;81(3):349-52.

17. Davis LE, Leveno KJ, Cunningham GF. Hypothyroidism complicating pregnancy. Obstetr Gynecol. 1988;72(1):108-13.

18. Stagnaro GA. Overt Hyperthyroidism and Hypothyroidism during pregnancy. Clin Obstetr Gynecol. 2011;54(3):478-87.

19. Abalovich M, Gutierrez S, Alcaraz G, Maccallini G, Garcia A, Levalle O. Overt and subclinical hypothyroidism complicating pregnancy. Thyroid. 2002;12(1):63-8.

20. Negro R, Schwartz A, Gismondi R, Tinelli A, Mangieri T, Stagnaro-Green A. Increased pregnancy loss rate in thyroid antibody negative women with TSH levels between 2.5 and 5.0 in the First Trimester of Pregnancy. J Clin Endocrinol Metabol. 2010;95(9):44-8.

21. Cleary Goldman J, Malone FD, Lambert Messerlian G, Sullivan L, Canick J, Porter TF, et al. Maternal thyroid hypofunction and pregnancy outcome. Obstetr Gynecol. 2008;112(1):85-92.

22. Goel P, Radotra A, Devi K, Malhotra S, Aggarwal A, Huria A. Maternal and perinatal outcome in pregnancy with hypothyroidism. Indian $\mathrm{J}$ Med Sci. 2005;59(3):116-7.

23. Kashi Z, Bahar A, Akha O, Hassanzade S, Esmaeilisaraji L, Hamzehgardeshi Z. Levothyroxine Dosage Requirement During Pregnancy in WellControlled Hypothyroid Women: A Longitudinal Study. Global J Health Sci. 2016;8(4):227-33. 
24. Alexander EK, Marqusee E, Lawrence J, Jarolim P, Fischer GA, Larsen PR. Timing and magnitude of increases in levothyroxine requirements during pregnancy in women with hypothyroidism. N Engl J Med. 2004;351(3):241-9.

25. Hallengren B, Lantz M, Andreasson B, Grennert L. Pregnant women on thyroxine substitution are often dysregulated in early pregnancy. Thyroid. 2009;19(4):391-4.

26. Kaplan MM. Management of thyroxine therapy during pregnancy. Endocrine Pract. 1996;2(4):281-6.

27. Mandel SJ. Hypothyroidism and chronic autoimmune thyroiditis in the pregnant state: Maternal aspects. Best Pract Res Clin Endocrinol Metabol. 2004;18(2):213-24.

28. Pekonen F, Teramo K, Ikonen E, Osterlund K, Makinen T, Lamberg BA. Women on thyroid hormone therapy: pregnancy course, fetal outcome, and amniotic fluid thyroid hormone level. Obstetr Gynecol. 1984;63(5):635-8.

29. Ain KB, Mori Y, Refetoff S. Reduced clearance rate of thyroxine-binding globulin (TBG) with increased sialylation: a mechanism for estrogen-induced elevation of serum TBG concentration. J Clin Endocrinol Metabol. 1987;65(4):689-96.

30. Huang SA. Physiology and pathophysiology of type 3 deiodinase in humans. Thyroid. 2005;15(8):875-81.

Cite this article as: Justin SA, Johnson MS. A prospective study on evaluation of maternal and foetal outcomes of hypothyroidism with levothyroxine and prevalence of hypothyroidism in pregnancy in a tertiary care teaching hospital in Kerala. Int J Basic Clin Pharmacol 2020;9:392-8. 